\title{
Prevalence and Patterns of Herbal Medicine Use among Type 2 Diabetes Mellitus Patients at the University Teaching Hospitals in Lusaka
}

\author{
Christabel Nang'andu Hikaambo ${ }^{*}$, Yvonne Namutambo ${ }^{1}$, Martin \\ Kampamba ${ }^{1}$, Webrod Mufwambi ${ }^{1}$, Reagan Kabuka ${ }^{2}$, Martha Chulu ${ }^{2}$, \\ Namuchindo Nanyangwe' ${ }^{3}$, Michelo Banda ${ }^{1}$, Tadious Chimombe ${ }^{1}$, \\ Lungwani Tyson Muungo ${ }^{1}$ and Steward Mudenda ${ }^{1}$ \\ 'Department of Pharmacy, School of Health Sciences, University of Zambia, Lusaka, Zambia \\ ${ }^{2}$ Department of Pharmacy, School of Health Sciences, Levy Mwanawasa Medical University, Lusaka, Zambia \\ ${ }^{3}$ Department of Medicines Control, Zambia Medicines Regulatory Authority, Lusaka, Zambia
}

\section{ABSTRACT}

Background: In 2015, Zambia reported 218,200 instances of Diabetes Mellitus (DM) with 8,232 diabetes-related fatalities. Insulin therapy and oral antidiabetic medications are two pharmacological therapies used to treat diabetes mellitus. Herbal medicine, on the other hand, has a lengthy history and is an easily accessible and economical therapeutic option. Patients with Type 2 Diabetes Mellitus (T2DM) are increasingly turning to herbal therapies as keeping to conventional regimens becomes more challenging.

Aim: We aimed to assess the prevalence and patterns of herbal medicine use among Type 2 diabetes mellitus patients at the University Teaching Hospital.

Methods: This cross-sectional study was conducted on 101 T2DM patients using a selfadministered questionnaire from August to October 2021. Data were analysed using Statistical Package for Social Science (SPSS) version 26.

Results: Of the 101 participants, $(n=93,92.1 \%)$ used herbal medicines. Garlic (Allium sativum) was the most widely used herbal medication (58.4\%), followed by Moringa (Moringa oleifera) at $42.6 \%$, and mule (Myrrh) at 5\%. The need to treat diabetes and other medical problems $(n=47,50.5 \%)$ was the main reason for herbal medicines use, followed by family tradition or culture $36(38.7 \%)$. The primary source of information about herbal medicines use was friends ( $n=46,45.5 \%$ ), followed by family members ( $n=38,37.6 \%)$. The majority $(n=83,82.2 \%)$ of the participants reported not having any adverse events from herbal medicines, and only $(n=10,9.9 \%)$ had experienced side effects.

Conclusion: There was a high use of herbal medicines among T2DM patients, particularly those aged between 45 and 76 years. From the standpoint of high prevalence and low disclosure rate, it is imperative for healthcare providers to strongly educate patients regarding the use of herbal medicines. In addition, the public needs to be educated on pharmacovigilance so that they know the importance of reporting adverse events, even those that may be associated with herbal medicines.

\section{BACKGROUND}

Diabetes Mellitus (DM) is a chronic metabolic disorder of carbohydrates, proteins, and fats occurring in the endocrine system due to absolute or relative deficiency of insulin secretion with/without varying degrees of insulin resistance [1-3]. There are two main types of DM, i.e. Type 1 DM (T1DM) and Type 2 DM (T2DM) [4]. Type 1 is characterised by insulin deficiency as a result of autoimmune destruction of pancreatic $\mathrm{B}$ cells while T2DM is due to insulin resistance and

\section{*Corresponding author}

Christabel Nang'andu Hikaambo, Department of Pharmacy, School of Health

Sciences, University of Zambia, Lusaka, Zambia

E-mail: xellhikaambo@gmail.com

DOI: $10.37871 /$ jbres1402

Submitted: 10 January 2022

Accepted: 18 January 2022

Published: 20 January 2022

Copyright: (c) 2022 Hikaambo CN, et al Distributed under Creative Commons CC-BY 4.0 (c)(i)

\section{OPEN ACCESS}

Keywords

$>$ Diabetes mellitus

$>$ Type 2 diabetes mellitus

$>$ Herbal medicines

$>$ Patterns

$>$ Prevalence

$>$ Adverse events

$>$ Pharmacovigilance

$>$ Zambia

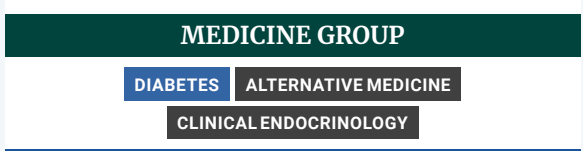

VOLUME: 3 ISSUE: 1 - JANUARY, 2022 
reduced insulin secretion [4,5]. The global prevalence of DM is approximately $8.3 \%$ with $\mathrm{T} 2 \mathrm{DM}$ contributing $90-95 \%$ of the cases [4].

Treatment of DM is dependent on the type that an individual is suffering from [6]. In modern medicine, insulin and oral antidiabetic agents such as sulfonylureas, biguanides, meglitinides, alpha-glycosidase inhibitors, thiazolidinediones, and incretin mimetics are critical in the management of T2DM [7]. However, oral therapies are known to have side effects in the long run and, particularly in developing countries, are expensive and not easily accessible [8]. This prevents T2DM patients from using oral therapies and resorting to using herbal medicines.

Plants have always been an exemplary source of drugs, and many of the currently available drugs have been derived directly or indirectly from them [9]. In recent years, herbal medicines have started to gain importance as a source of hypoglycemic agents. Herbal medicine is defined by the World Health Organization (WHO) as a practice that includes herbs, herbal materials, herbal preparations, and finished herbal products that contain active ingredients that are parts of plants or other plant materials or combinations [10]. They are derived from plant parts such as leaves, stems, flowers, roots, and seeds [11]. They contain active ingredients scientifically known as phytochemicals that include several classes, such as saponins, flavonoids, glycosides, tannins, alkaloids, and terpenoids [12]. Marles and Farnsworth estimated that more than 1000 plant species are being used as folk medicine for DM [13]. Examples of herbal medicines that possess hypoglycemic properties include Allium sativum (Garlic), Eleutherococcus senticosus (Ginseng), Azadirachta indica (Neem), Cinnamomum verum (Cinnamon) and Beta vulgaris (Beet) [8].

There has been a rise in the use of herbal medicines by diabetic patients due to their cultural acceptability, availability, and safety claims. Furthermore, there has been an increase in the use of herbs as prescription drugs in developed countries such as France and Germany [8]. The products of herbal medicines have a long history of being safe [14], but the misuse of these medicines may lead to adverse events [15]. In some countries, especially in the developing world, toxicological assessment of herbal medicines and associated products is not conducted before being placed on the market. This is because there is a belief that all herbal medicines are safe for use [16].

In sub-Saharan Africa, the prevalence of diabetes was approximated to be between $2.9 \%$ and $9.4 \%$ [17]. However, a higher prevalence of approximately $10.9 \%$ was reported in the Middle East and North African regions (4). In Ethiopia, the prevalence of DM was reported to be 3.3\% [18]. T2DM has continued to be a burden in Africa causing increased morbidity, mortality and increased medical costs [19]. In 2015, Zambia, a developing country, reported approximately 218,200 cases of DM with 8,232 diabetes-related fatalities
[20]. The prevalence of diabetes among Zambian adults was around 3.5\% [17]. Patients with T2DM are increasingly turning to the use of herbal medicines as keeping to conventional regimens becomes more challenging.

This study aimed to assess the prevalence and patterns of herbal medicine use among type 2 diabetes mellitus patients at the University Teaching Hospital.

\section{MATERIALS AND METHODS}

\section{Study design, site and population}

This was a cross-sectional study that employed a quantitative approach and was conducted between August $13^{\text {th }}$ and October $13^{\text {th }}, 2021$. The study was conducted at the University Teaching Hospitals (UTH) in Lusaka because it is the highest referral centre with a patient coverage of about 1,000,000 and about 1000 diabetic patients.

\section{Sample size and sampling method}

This study utilised a convenient sampling method. Only the diabetic patients who were available during the data collection period and consented to participate in the study were recruited. From the data collection period, the possible number of patients who had clinical appointments was about 135 , which gives the total sample population. Slovin's formula was used to determine the sample size. Therefore, using a population of 135 at a $95 \%$ confidence level and a margin error of $5 \%$, the calculated sample size was found to be 101 .

\section{Data collection approach and tool}

A structured self-administered questionnaire adapted and modified from previous studies on herbal medicine use among T2DM patients was used $[21,22]$. The questionnaire was divided into three sections: socio-demographic and health information; common medicinal herbs used and reasons for using them; and characteristics of the herbal medicine used. Key questions asked included the reasons respondents had for using herbal medicines, who informed them about herbal medicine use, and if they had informed their health care providers about their use of herbal medicines. Data collection was conducted by 2 data collectors who were trained and monitored during the collection process. The interview took between 20 and 30 minutes.

\section{Data analysis}

All questionnaire responses were entered into Microsoft Excel, where the responses were cross-checked for consistency. Questionnaires that had incomplete data were rejected as non-complete. Then the data was exported to the Statistical Package for Social Sciences (SPSS) version 24. Descriptive statistics like the different herbal medicines were presented in tables. Other study variables were represented in pie charts and bar graphs. 


\section{Ethical considerations}

Ethical approval to conduct this study at the University Teaching Hospital was obtained from the University of Zambia Health Sciences Research Ethics Committee (UNZAREC) with protocol ID number 202112030074. Furthermore, permission to collect data was obtained from the medical superintendent at the adult hospital of the University Teaching Hospital in Lusaka. Consent was also obtained from the participants who agreed to participate in the study. Participants were informed about the nature of the study before the commencement of questionnaire administration. Patients were assured that any information they would reveal would remain confidential and be used strictly for research purposes only.

\section{RESULTS}

\section{Socio-demographic characteristics of respondents}

From table 1, it can be deduced that the age range of all the $101 \mathrm{~T} 2 \mathrm{DM}$ respondents was from below 30 years to above 75 years. The table also indicates that the majority of the respondents were in the age range of 45 to 59 which was represented by $(n=36,35.6 \%)$ of the total respondents. The table also shows that more than half of the respondents (51.5\%) were males and $48.5 \%$ were females. By tribe, the majority were Bemba (20.8\%). The majority of these

Table 1: Socio-demographic characteristics of type 2 DM Respondents $(n=$ 101).

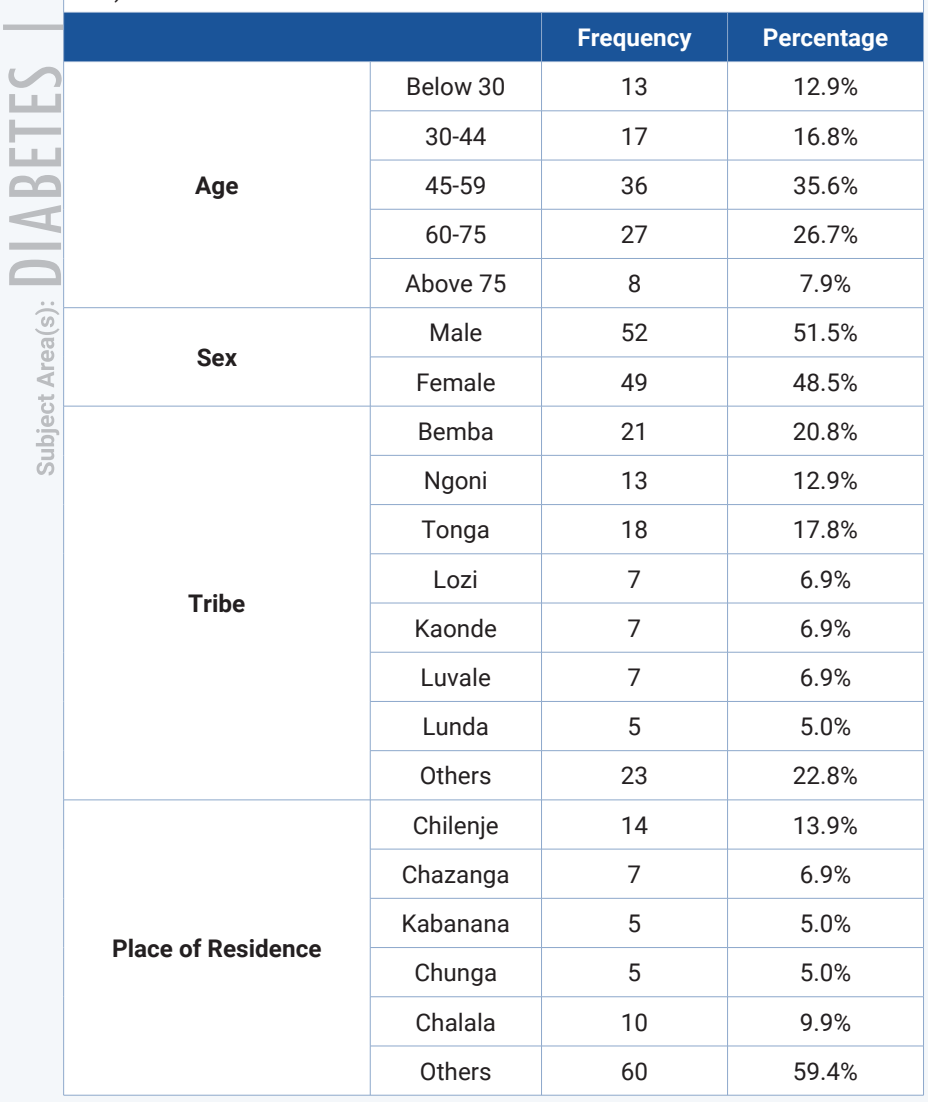

respondents came from Chilenje Township which was represented by $13.9 \%$ followed by Chalala (9.9\%).

\section{Herbal medicine usage among respondents}

Of the total participants, $(n=93,92.1 \%)$ stated that they used Herbal Medicine (HM) against DM. From the total HM users, the majority of them represented by $(n=55,59.1 \%)$ were those with an average monthly income of below 1000 Zambian Kwacha (ZMK) as compared to those that earn on average above $1000 \mathrm{ZMK}(40.9 \%)$. The table also indicated that the majority of HM users were entrepreneurs $(n=42$, $45.2 \%$ ), followed by unemployed ( $n=30,32.3 \%$ ). It was also noted that those that had reached a secondary level of education were the majority users of HM (36.6\%). Of the 93 HM users, ( $n=66,71.0 \%$ ) had a family history of DM and were diagnosed with DM in less than 5 years of having the condition (61.3\%). Most of these were diagnosed with DM when they were more than 30 years of age $(n=81,87.1 \%)$ and $(n=44,47.3 \%)$ reported having had bad control of blood sugar as shown in table 2.

\section{Types of Herbal Medicines used among DM patients}

As shown in figure 1, the most commonly used herbal medicine was garlic (Allium sativum) $(n=59,58.4 \%)$, followed by moringa (Moringa oleifera) ( $n=43,42.6 \%$ ). Other HM used were itembusha (Aloe spp) $(n=34,33.7 \%)$, mango (Mangifera indica) leaves ( $n=31,30.7 \%)$, cinnamon (Cinnamomum verum) and guava (Psidium guajava) leaves had ( $n=30,29.7 \%$ ) each, turmeric(Curcuma longa) ( $n=21$, $20.8 \%$ ), lemon grass (Cymbopogon citratus) $(n=15,14.9 \%)$, parsley $(n=10,9.9 \%)$, coriander(Coriandrum sativum) $(n=9$, $8.9 \%$ ) and the least used herbal medicine was Mule (Myrrh), which was represented by $(n=5,5.0 \%)$. Other herbs that were used included lemon fruit (Citrus limon), bitter gourd (Momordica charantia) and bondwe (amaranth spp), which were represented by $32.7 \%$.

\section{The pattern of use of Herbal Medicines among T2DM patients}

The need to treat diabetes and other medical problems ( $n=47,50.5 \%$ ) was the main reason for herbal medicine use among DM patients followed by family tradition or culture ( $n=36,38.7 \%$ ). Those that had beliefs in the advantages of these herbal medicines were represented by $(n=28,30.1 \%)$, Herb's accessibility and availability $(n=24,25.8 \%)$ and those that were dissatisfied with conventional therapy were only $(n=3,3.2 \%)$ and other reasons $(n=8,8.6 \%)$. It was also noted that among HM non-users, all of them ( $n=8,100 \%)$ had satisfaction with Conventional Therapy (CT) as the main reason why they could not use herbal medicine as shown in figure 2. 
Table 2: Herbal medicine usage among type 2 DM respondents.

\begin{tabular}{|c|c|c|c|c|c|}
\hline & & \multicolumn{4}{|c|}{ Do you use Herbal Medicines? } \\
\hline & & \multicolumn{2}{|c|}{ Yes $(93,92.1 \%)$} & \multicolumn{2}{|c|}{ No $(8,7.9 \%)$} \\
\hline & & Frequency & Percentage & Frequency & Percentage \% \\
\hline \multirow{2}{*}{$\begin{array}{l}\text { Average Monthly Income } \\
\text { (ZMK) }\end{array}$} & $<1000$ & 55 & $59.1 \%$ & 3 & $37.5 \%$ \\
\hline & $>1000$ & 38 & $40.9 \%$ & 5 & $62.5 \%$ \\
\hline \multirow{4}{*}{ Employment Status } & Unemployed & 30 & $32.3 \%$ & 4 & $50.0 \%$ \\
\hline & Entrepreneur & 42 & $45.2 \%$ & 4 & $50.0 \%$ \\
\hline & Employed & 15 & $16.1 \%$ & 0 & $0.0 \%$ \\
\hline & Retired & 6 & $6.5 \%$ & 0 & $0.0 \%$ \\
\hline \multirow{4}{*}{ Patient Education } & Nil & 21 & $22.6 \%$ & 2 & $25.0 \%$ \\
\hline & Primary & 28 & $30.1 \%$ & 0 & $0.0 \%$ \\
\hline & Secondary & 34 & $36.6 \%$ & 3 & $37.5 \%$ \\
\hline & Tertiary & 10 & $10.8 \%$ & 3 & $37.5 \%$ \\
\hline \multirow{2}{*}{ Family History Of DM } & No & 27 & $29.0 \%$ & 2 & $25.0 \%$ \\
\hline & Yes & 66 & $71.0 \%$ & 6 & $75.0 \%$ \\
\hline \multirow{6}{*}{ Duration of DM } & $<5$ & 57 & $61.3 \%$ & 7 & $87.5 \%$ \\
\hline & $5-9$ & 19 & $20.4 \%$ & 0 & $0.0 \%$ \\
\hline & $10-14$ & 10 & $10.8 \%$ & 0 & $0.0 \%$ \\
\hline & $15-19$ & 2 & $2.2 \%$ & 0 & $0.0 \%$ \\
\hline & $20-24$ & 4 & $4.3 \%$ & 1 & $12.5 \%$ \\
\hline & $>25$ & 1 & $1.1 \%$ & 0 & $0.0 \%$ \\
\hline \multirow{2}{*}{ Age Diagnosed With DM } & less than 30 & 12 & $12.9 \%$ & 1 & $12.5 \%$ \\
\hline & greater than 30 & 81 & $87.1 \%$ & 7 & $87.5 \%$ \\
\hline \multirow{3}{*}{ Control of Blood Sugar } & Good & 12 & $12.9 \%$ & 0 & $0.0 \%$ \\
\hline & Bad & 44 & $47.3 \%$ & 3 & $37.5 \%$ \\
\hline & Varies & 37 & $39.8 \%$ & 5 & $62.5 \%$ \\
\hline
\end{tabular}

TYPE OF HM USED

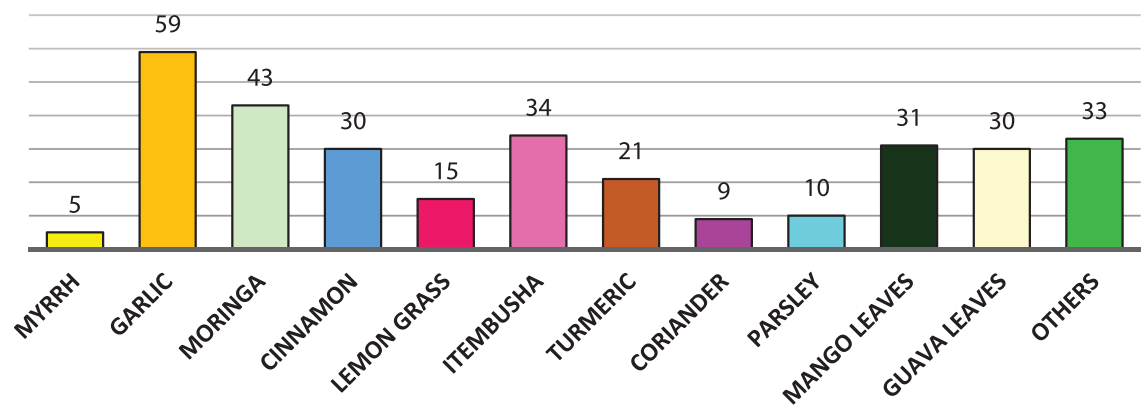

$\begin{array}{llll}\square \text { Myrrh } & \square \text { Garlic } & \square \text { Moringa } & \square \text { Cinnamon } \\ \square \text { Lemon Grass } & \square \text { Itembusha } & \square \text { Turmeric } & \square \text { Coriander } \\ \square \text { Parsley } & \square \text { Mango Leaves } & \square \text { Guava Leaves } & \square \text { Others }\end{array}$

Figure 1 Types of herbal medicines used among DM participants.

\section{Herbal medicine use and its outcome among T2DM patients}

As shown in table 3 in this study, of all the participants who used Herbal Medicine (HM), their primary source of information about HM were friends ( $n=46,45.5 \%$ ) followed by family members $(n=38,37.6 \%)$, other sources $(n=10$, $9.9 \%)$, and traditional healers $(n=7,6.9 \%)$. Those that reported using HM weekly were $(n=37,36.6 \%)$, followed by those using daily ( $n=26,25.7 \%$ ). Most of the participants used HM alongside conventional prescribed medicines
$(49.5 \%)$. Of the users, $(n=83,82.2 \%)$ reported not having experienced any adverse events when they used herbs, $(n=$ $10,9.9 \%$ ) had experienced adverse events and only ( $n=8$, $7.9 \%$ ) were not sure if they had experienced any side effects.

It was established that $82.2 \%$ of the respondents reported that they had not discussed with their healthcare providers the use of herbal medicines. This was because most respondents anticipated a negative response $(n=63$, $62.4 \%$ ) from their doctors, followed by not having sufficient information about the HM $(n=12,11.9 \%)$ and not important 


\begin{tabular}{|c|c|c|c|}
\hline $\begin{array}{l}\text { 口Tradition \& Culture } \\
\text { वHM accessible \& Available } \\
\text { वDissatifaction with CT }\end{array}$ & \multicolumn{3}{|c|}{$\begin{array}{l}\text { 口Beliefs in HM advantages } \\
\text { वTreatment of DM \& Other conditions }\end{array}$} \\
\hline & & Frequency & Percentage \\
\hline \multirow{4}{*}{ Who recommended HM for you? } & $\begin{array}{l}\text { Traditional } \\
\text { Healer }\end{array}$ & 7 & $6.9 \%$ \\
\hline & Friend & 46 & $45.5 \%$ \\
\hline & Family & 38 & $37.6 \%$ \\
\hline & Other & 10 & $9.9 \%$ \\
\hline \multirow{3}{*}{ How often do you use HM? } & Daily & 26 & $25.7 \%$ \\
\hline & Weekly & 37 & $36.6 \%$ \\
\hline & Others & 38 & $37.6 \%$ \\
\hline \multirow{3}{*}{ Experience adverse events } & Yes & 10 & $9.9 \%$ \\
\hline & No & 83 & $82.2 \%$ \\
\hline & Not Sure & 8 & $7.9 \%$ \\
\hline \multirow{3}{*}{$\begin{array}{l}\text { Used along with prescribed } \\
\text { medicines }\end{array}$} & Yes & 50 & $49.5 \%$ \\
\hline & No & 44 & $43.6 \%$ \\
\hline & Sometimes & 7 & $6.9 \%$ \\
\hline \multirow{2}{*}{ Intend to use it again } & Yes & 75 & $74.3 \%$ \\
\hline & No & 26 & $25.7 \%$ \\
\hline \multirow{2}{*}{ Satisfaction with use } & Yes & 76 & $75.2 \%$ \\
\hline & No & 25 & $24.8 \%$ \\
\hline
\end{tabular}

for doctors to know $(n=10,11.8 \%)$ as shown in table 4 .

\section{DISCUSSION}

The purpose of this study was to assess the prevalence and patterns of herbal medicine use among type 2 Diabetes Mellitus (T2DM) patients at the University Teaching Hospitals. The study found that the majority of the respondents were in the age range of 45 to 59 , which was represented by $35.6 \%$ of the total respondents. The sample of our study population is similar in age to a study by Iglay and colleagues where the mean age for patients with T2DM was 65 years old [23]. This shows that the age distribution in our study and the cited study were similar.

Herbal medicines have been used throughout human history, even with the development of conventional medicines. The use of herbal medicines to treat various diseases such as DM is still high, especially in developing

\begin{tabular}{|c|c|c|c|}
\hline Table 4: Reasons for not informing the doctor about herbal medicine use. \\
\hline \multirow{2}{*}{$\begin{array}{c}\text { Have you informed your doctor or health } \\
\text { professional }\end{array}$} & Yes & 18 & $17.8 \%$ \\
\cline { 2 - 4 } & No & 83 & $82.2 \%$ \\
\hline \multirow{2}{*}{$\begin{array}{c}\text { Anticipating negative response } \\
\text { Yes }\end{array}$} & 63 & $62.4 \%$ \\
\cline { 2 - 4 } & No & 30 & $29.7 \%$ \\
\hline \multirow{2}{*}{ Insufficient information on herbal medicine } & 4 & 8 & $7.9 \%$ \\
\cline { 2 - 4 } & Yes & 12 & $11.9 \%$ \\
\hline \multirow{2}{*}{$\begin{array}{c}\text { A doctor doesn't have to know about my } \\
\text { herbal medicine use }\end{array}$} & Yes & 10 & $9.9 \%$ \\
\cline { 2 - 4 } & No & 91 & $90.1 \%$ \\
\hline
\end{tabular}

countries like Zambia. This study found a high prevalence (92\%) of herbal medicine use among T2DM patients. In Ethiopia, a study reported different findings in which $62 \%$ of T2DM patients used herbal medicines [24]. In Tanzania, $67.2 \%$ of diabetic patients used herbal medicines to manage their blood sugar [25]. The high use of herbal medicines in these studies could be attributed to strong cultural beliefs and personal experiences [26]. Besides, some T2DM patients possess some scientific knowledge regarding the use of herbal medicines in addition to conventional medicines [26]. According to a similar study conducted in Ethiopia, those with a family history of diabetes were nearly three times more likely to use traditional medicines than those without a family history of herbal medicine use in diabetes [27]. This is similar to a study in Jamaica where $98 \%$ of the respondents used herbal medicines [28]. In the current study, 51.5\% of the herbal medicine users were males. In contrast, some studies have reported that being a woman and being middleaged is associated with herbal medicine use [29,30]. Women in most societies are the primary decision-makers in family healthcare and are more open to alternatives than men [31]. This study found that the level of education was related to herbal medicine use, as was the family background.

From our study, the most commonly used herbs are garlic (Allium sativum), moringa (Moringa oleifera), itembusha (Aloe spp), mango leaves (Mangifera indica), cinnamon (Cinnamomum verum) and guava leaves (Psidium guajava). According to a study in Tanzania, the most preferred herbal products were Moringa oleifera, Cymbopogon citrullus, Hagenia abyssinica, Aloe vera, and Clausena anisata [32]. Studies in Ethiopia and Sudan also found that Aloe spp. and Allium sativum were among the most commonly used herbal medicines $[22,27,33]$. In a systematic review of herbs and supplements clinically used for glycemic control, Allium sativum, Aloe vera, and Momordica charantia were the only identified plants used in Nigeria. This inclusion was, however, based on clinical studies carried out outside Nigeria [34]. One of the reasons why the named herbs are most commonly used is because they grow in almost all environments, are readily available on the market, and because of their nutritional and health value. 
Cinnamon and fenugreek were the most commonly used herbs not only in the Kingdom of Saudi Arabia (KSA) but also in other Arabic countries such as Bahrain, Oman, Iraq, and Jordan [35]. A study in Turkey also found cinnamon to be the most preferred herbal product [36]. This is because they are widely available in these countries. Similarly, in Iran and Sudan, cinnamon and fenugreek were the most common medicinal plants used by diabetic patients, respectively $[22,37]$. Since easy access to some medicinal plants can play an important role in their use, the prevalence of different medicinal plants in various regions can be explained. Also, the application of some medicinal plants in cooking may increase their usage. For example, cinnamon is one medicinal plant that is sold in most retail shops and is used as a spice [38].

Despite having many reports on the use of medicinal plants for the management of T2DM [39-42], to date, little is known about the applicability of mango leaves in treating various diseases [43,44]. Guava (Psidium guajava) has been used as a health tea. The leaves contain copious amounts of phenolic phytochemicals and therefore can be expected to prevent various chronic diseases such as diabetes, cancer, and heart diseases [45].

In contrast, as herbal product use rates may vary for various reasons, including cultural aspects, the preferred herbal product may change among countries and communities. For instance, according to [46] in Chipulukusu Compound, Ndola, Zambia, the most commonly used plants in the treatment of diabetes were Erythrina abyssinica, Kigelia africana, Bidens pilosa, Carica papaya, Azaza garckeana, and Mangifera indica. Similarly, bitter gourd and misai kucing were the most commonly used herbs in Malaysia, owing to cultural and geographical differences [47].

This study established that the need to treat diabetes and other medical problems $(50.5 \%)$ was the main reason for herbal medicine use among T2DM patients. This was followed by family tradition or culture $(38.7 \%)$, beliefs in the advantages of these herbal medicines $(30.1 \%)$, the herb's accessibility and availability (25.8\%) and dissatisfaction with conventional therapy (3.2\%). This is similar to a study conducted in Malaysia which reported that the need to achieve better control of diabetes was the main reason for use of complementary and alternative medicines [48]. However, a study in Egypt established that the belief in the benefits of complementary and alternative medicines was the main reason for use in T2DM patients [49]. Dissatisfaction with modern therapy and beliefs in the merits of herbal medicines were the key reasons for herbal medicine use as reported in another study [24]. A high rate of dissatisfaction with conventional therapy was also observed in Lebanon and the United Arab Emirates (UAE) as the reason for herbal medicine use $[50,51]$.

Our study established that the primary sources of information about herbal medicine use were friends
(45.5\%), followed by family members (37.6\%) and traditional healers $(6.9 \%)$. Our findings are similar to the findings in Saudi Arabia, where it was reviewed that the primary source of information was from family and friends, and other sources included social media and websites [31]. Additionally, Mekuria, et al. [24] also reported that family and friends were the main sources of information about herbal medicine use. However, in a diabetic care service of Debre Tabor General Hospital, located in Debre Tabor town, South Gondar zone, Northwest Ethiopia, they found that patients using herbal medicines were the primary source of information, while family and friends stood in second place as sources of information [27]. The differences observed could be as a result of differences in geographical locations and cultural practices.

Additionally, $49.5 \%$ of the respondents indicated that they use herbal medicines along with conventional therapy. However, $82.2 \%$ of them did not inform their doctors or health professionals about the use of herbal medicines. $62.4 \%$ of those who didn't inform their doctors believed that they would be discouraged from using them if they informed their doctors. However, $11.8 \%$ of herbal medicine users stated that it was not important for their doctors to know about it. The findings of the concomitant use of herbal medicines with oral hypoglycemic agents are similar to several studies in Morocco [27], Saudi Arabia [31] and Russia [52]. As demonstrated in our study, patients were sceptical about informing doctors and healthcare professionals about their use of herbal medicine because they believed they would not be supported to use the herbs [31], had insufficient information, and believed the doctor did not need to know [27]. The major reason cited by [24] for not discussing with the doctor was due to forestalling negative responses about herbal medicine use. In contrast, a study done in Iran reported that the patients informed their doctors and health professionals on the use of herbal medicines [53].

The current study further found that only $9.9 \%$ of the herbal medicine users experienced adverse events, and $75.2 \%$ were very satisfied with the use of herbal medicines. This is in line with another study where they found that most individuals who consume herbs did not report any adverse events because of the belief that they are safe [36]. Besides, individuals fear losing their good relationship with healthcare workers [54]. However, evidence has shown that the consumption of herbs can be associated with the occurrence of adverse events [55]. It is imperative to note that many consumers of herbs are not aware that they can report adverse events to the healthcare authorities or the national pharmacovigilance units [56]. Reporting of adverse events to the national pharmacovigilance units can improve patient safety $[57,58]$.

\section{CONCLUSION}

Herbal medicine use among Type 2 Diabetes patients is prevalent at the University Teaching Hospitals. Our study 
showed that $93 \%$ of the patients with diabetes mellitus used herbal medicines. It is important to state that all these patients were assumed to be on conventional therapies as the study targeted patients who were seen from the hospital. Many of the patients took the herbal medicines with the view of treating the disease while others took herbal medicines as it was culturally acceptable. Allium sativum (garlic) was the most commonly taken herbal medicine followed by moringa (Moringa oleifera). The public should be educated on the use of herbal medicines and also informed on the channels of reporting adverse events after taking herbs.

\section{RECOMMENDATIONS}

- There is a strong need to sensitize communities on the dangers of taking herbal medications with conventional medicines concomitantly without advice from healthcare workers.

- Communities should also be sensitized on the consequences of taking the unapproved herbal medication.

- Prescribers should enhance the patients' review process to establish whether their patients are taking herbal medications besides the conventional therapies.

\section{REFERENCES}

. Dipiro JT, Talbert RL, Yee GC, Matzke GR, Wells BG, Posey LM. Pharmacotherapy: a pathophysiologic approach. Ed. McGraw-Hill Medical, New York; 2014

2. Dilworth L, Facey A, Omoruyi F. Diabetes Mellitus and Its Metabolic Complications: The Role of Adipose Tissues. Int J Mol Sci. 2021 Jul 16;22(14):7644. doi: 10.3390/ ijms22147644. PMID: 34299261; PMCID: PMC8305176.

3. Sun $Y$, Ma C, Sun H, Wang H, Peng W, Zhou Z, Wang H, Pi C, Shi Y, He X. Metabolism: A Novel Shared Link between Diabetes Mellitus and Alzheimer's Disease. J Diabetes Res. 2020 Jan 29;2020:4981814. doi: 10.1155/2020/4981814. PMID: 32083135; PMCID: PMC7011481.

4. Kharroubi AT, Darwish HM. Diabetes mellitus: The epidemic of the century. World J Diabetes. 2015 Jun 25;6(6):850-67. doi: 10.4239/wjd.v6.i6.850. PMID: 26131326; PMCID: PMC4478580

5. Ritter JM, Rang HP, Flower RJ, Henderson G. Rang \& Dale's Pharmacology E-Book: with STUDENT CONSULT Online Access: Elsevier Health Sciences; 2014.

6. Tan SY, Mei Wong JL, Sim YJ, Wong SS, Mohamed Elhassan SA, Tan SH, Ling Lim GP, Rong Tay NW, Annan NC, Bhattamisra SK, Candasamy M. Type 1 and 2 diabetes mellitus: A review on current treatment approach and gene therapy as potentia intervention. Diabetes Metab Syndr. 2019 Jan-Feb;13(1):364-372. doi: 10.1016/j. dsx.2018.10.008. Epub 2018 Oct 10. PMID: 30641727

7. Toklu HZ. Herbal medicine use among diabetes mellitus patients in Northern Cyprus. Journal of Medicinal Plants Research. 2013;7(22):1652-1664. doi: 10.5897/ JMPR12.1207.

8. Benzie IFF W-GS. Herbal Medicine: Biomolecular and Clinical Aspects. $2^{\text {nd }}$ ed. CRC Press/Taylor \& Francis; 2011

9. Tag H, Kalita P, Dwivedi P, Das AK, Namsa ND. Herbal medicines used in the treatment of diabetes mellitus in Arunachal Himalaya, northeast, India. J Ethnopharmacol. 2012 Jun 14;141(3):786-95. doi: 10.1016/j.jep.2012.03.007. Epub 2012 Mar 13. PMID: 22433536 .

10. WHO. World Health Organization General Guidelines for Methodologies on Research and Evaluation of Traditional Medicine. WHO: Geneva. 2000.

11. Bent S. Herbal medicine in the United States: review of efficacy, safety, and regulation grand rounds at University of California, San Francisco Medical Center. J Gen Intern Med. 2008 Jun;23(6):854-9. doi: 10.1007/s11606-008-0632-y. Epub 2008 Apr 16. PMID: 18415652; PMCID: PMC2517879.
12. Saxena M, Saxena J, Nema R, Singh D, Gupta A. Phytochemistry of medicinal plants Journal of pharmacognosy and phytochemistry. 2013;1(6). https://bit.ly/34MsLv4

13. Marles RJ, Farnsworth NR. Antidiabetic plants and their active constituents Phytomedicine. 1995 Oct;2(2):137-89. doi: 10.1016/S0944-7113(11)80059-0. PMID: 23196156

14. Moreira DdL, Teixeira SS, Monteiro MHD, De-Oliveira ACA, Paumgartten FJ. Erratum on" Traditional use and safety of herbal medicines". Revista Brasileira de Farmacognosia. 2014;24:502-3.

15. George P. Concerns regarding the safety and toxicity of medicinal plants-An overview. Journal of applied pharmaceutical science. 2011;1(6):40-4. https://bit.ly/3I2vT4u

16. Ekor $M$. The growing use of herbal medicines: issues relating to adverse reactions and challenges in monitoring safety. Front Pharmacol. 2014 Jan 10;4:177. doi: 10.3389/ fphar.2013.00177. PMID: 24454289; PMCID: PMC3887317.

17. Bailey SL, Ayles H, Beyers N, Godfrey-Faussett $P$, Muyoyeta M, du Toit E, Yudkin JS, Floyd S. Diabetes mellitus in Zambia and the Western Cape province of South Africa: Prevalence, risk factors, diagnosis and management. Diabetes Res Clin Pract. 2016 Aug;118:1-11. doi: 10.1016/j.diabres.2016.05.001. Epub 2016 May 7. PMID: 27485851; PMCID: PMC4994576.

18. Animaw W, Seyoum Y. Increasing prevalence of diabetes mellitus in a developing country and its related factors. PLoS One. 2017 Nov 7;12(11):e0187670. doi: 10.1371/ journal.pone.0187670. PMID: 29112962; PMCID: PMC5675402.

19. Godman B, Basu D, Pillay Y, Mwita JC, Rwegerera GM, Anand Paramadhas BD, Tiroyakgosi C, Okwen PM, Niba LL, Nonvignon J, Sefah I, Oluka M, Guantai AN, Kibuule D, Kalemeera F, Mubita M, Fadare J, Ogunleye 00, Distiller LA, Rampamba EM, Wing J, Mueller D, Alfadl A, Amu AA, Matsebula Z, Kalungia A, Zaranyika T, Masuka N, Wale J, Hill R, Kurdi A, Timoney A, Campbell S, Meyer JC. Review of Ongoing Activities and Challenges to Improve the Care of Patients With Type 2 Diabetes Across Africa and the Implications for the Future. Front Pharmacol. 2020 Mar 20;11:108. doi: 10.3389/ fphar.2020.00108. PMID: 32265688; PMCID: PMC7098994.

20. Atlas D. International diabetes federation. IDF Diabetes Atlas, $7^{\text {th }}$ ed. Brussels, Belgium: International Diabetes Federation. 2015.

21. Al-Rowais NA. Herbal medicine in the treatment of diabetes mellitus. Saudi Med J. 2002 Nov;23(11):1327-31. PMID: 12506289.

22. Ali BAM, Mahfouz MS. Herbal medicine use among patients with type 2 diabetes in North Sudan. Annual Research \& Review in Biology. 2014:1827-38. https://bit. ly/3qv1vcZ

23. Iglay K, Hannachi H, Joseph Howie P, Xu J, Li X, Engel SS, Moore LM, Rajpathak $\mathrm{S}$. Prevalence and co-prevalence of comorbidities among patients with type 2 diabetes mellitus. Curr Med Res Opin. 2016 Jul;32(7):1243-52. doi: 10.1185/03007995.2016.1168291. Epub 2016 Apr 4. PMID: 26986190.

24. Mekuria AB, Belachew SA, Tegegn HG, Ali DS, Netere AK, Lemlemu E, Erku DA. Prevalence and correlates of herbal medicine use among type 2 diabetic patients in Teaching Hospital in Ethiopia: a cross-sectional study. BMC Complement Altern Med. 2018 Mar 9;18(1):85. doi: 10.1186/s12906-018-2147-3. PMID: 29523120; PMCID: PMC5845232.

25. Kasole R, Martin HD, Kimiywe J. Traditional Medicine and Its Role in the Management of Diabetes Mellitus: "Patients' and Herbalists' Perspectives". Evid Based Complement Alternat Med. 2019 Jul 4;2019:2835691. doi: 10.1155/2019/2835691. PMID: 31354852; PMCID: PMC6637672.

26. Coulter ID, Willis EM. The rise and rise of complementary and alternative medicine: a sociological perspective. Med J Aust. 2004 Jun 7;180(11):587-9. doi: 10.5694/j.13265377.2004.tb06099.x. PMID: 15174992

27. Kifle ZD, Bayleyegn B, Yimer Tadesse T, Woldeyohanins AE. Prevalence and associated factors of herbal medicine use among adult diabetes mellitus patients at government hospital, Ethiopia: An institutional-based cross-sectional study. Metabol Open. 2021 Aug 26;11:100120. doi: 10.1016/j.metop.2021.100120. PMID: 34485891; PMCID: PMC8403751.

28. Adeniyi O, Washington L, Glenn CJ, Franklin SG, Scott A, Aung M, Niranjan SJ, Jolly PE. The use of complementary and alternative medicine among hypertensive and type 2 diabetic patients in Western Jamaica: A mixed methods study. PLoS One. 2021 Feb 8:16(2):e0245163. doi: 10.1371/journal.pone.0245163. PMID: 33556053; PMCID: PMC7870151.

29. Nur N. Knowledge and behaviours related to herbal remedies: a cross-sectional epidemiological study in adults in Middle Anatolia, Turkey. Health Soc Care Community. 2010 Jul;18(4):389-95. doi: 10.1111/j.1365-2524.2010.00911.x. Epub 2010 Mar 15. PMID: 20345888

30. Peltzer K, Nguyen Huu T, Bach Ngoc N, Pengpid S. The use of herbal remedies and supplementary products among chronic disease patients in Vietnam. Studies on Ethno-Medicine. 2017;11(2):137-45. doi: 10.1080/09735070.2017.1305230 
31. Alqathama A, Alluhiabi G, Baghdadi H, Aljahani L, Khan O, Jabal S, Makkawi S, Alhomoud F. Herbal medicine from the perspective of type II diabetic patients and physicians: what is the relationship? BMC Complement Med Ther. 2020 Feb 28;20(1):65. doi: 10.1186/s12906-020-2854-4. PMID: 32111222; PMCID: PMC7076897.

32. Lunyera J, Wang D, Maro V, Karia F, Boyd D, Omolo J, Patel UD, Stanifer JW Comprehensive Kidney Disease Assessment For Risk factors, epidemiology, Knowledge, and Attitudes (CKD AFRiKA) Study. Traditional medicine practices among community members with diabetes mellitus in Northern Tanzania: an ethnomedical survey. BMC Complement Altern Med. 2016 Aug 11;16(1):282. doi: 10.1186/s12906016-1262-2. PMID: 27514380; PMCID: PMC4982437.

33. Amaeze OU, Aderemi-Williams RI, Ayo-Vaughan MA, Ogundemuren DA, Ogunmola DS, Anyika EN. Herbal medicine use among Type 2 diabetes mellitus patients in Nigeria: understanding the magnitude and predictors of use. Int J Clin Pharm. 2018 Jun;40(3):580-588. doi: 10.1007/s11096-018-0648-2. Epub 2018 May 2. PMID: 29721742

34. Yeh GY, Eisenberg DM, Kaptchuk TJ, Phillips RS. Systematic review of herbs and dietary supplements for glycemic control in diabetes. Diabetes Care. 2003 Apr;26(4):1277-94. doi: 10.2337/diacare.26.4.1277. PMID: 12663610

35. Alsanad S, Aboushanab T, Khalil M, Alkhamees OA. A Descriptive Review of the Prevalence and Usage of Traditional and Complementary Medicine among Saudi Diabetic Patients. Scientifica (Cairo). 2018 Aug 29;2018:6303190. do: 10.1155/2018/6303190. PMID: 30228928; PMCID: PMC6136479.

36. Başer T, Aypak C, Görpelioğlu S. Use of Herbal Products in Type 2 Diabetes Mellitus Patients. Family Medicine and Care. 2018. doi: 10.15761/FMC.1000106.

37. Azizi-Fini I, Adib-Hajbaghery M, Gharehboghlou Z. Herbal medicine use among patients with type 2 diabetes in Kashan, Iran, 2015. European Journal of Integrative Medicine. 2016;8(4):570-5. doi: 10.1016/j.eujim.2016.04.003.

38. Kiefer D, Tellez-Girón P, Bradbury EJ. A pilot study of herbal medicine use in Midwest Latino population. WMJ. 2014 Apr;113(2):64-71. PMID: 24908901; PMCID: PMC4212979.

39. Jayaprasad B, Thamayandhi D, Sharavanan PS. Traditionally using antidiabetic medicinal plants in Tamil Nadu. International Journal of Research in Pharmaceutical and Biosciences. 2012;2(1):1-8. https://bit.ly/33qcGuS

40. Rao MU, Sreenivasulu M, Chengaiah B, Reddy KJ, Chetty CM. Herbal medicines fo diabetes mellitus: a review. Int J PharmTech Res. 2010;2(3):1883-92. https://bit ly/3nyAKIZ

41. Nair SS, Kavrekar V, Mishra A. In vitro studies on alpha-amylase and alpha-glucosidase inhibitory activities of selected plant extracts. European Journal of Experimental Biology. 2013;3(1):128-32.

42. Girón MD, Sevillano N, Salto R, Haidour A, Manzano M, Jiménez ML, Rueda R, LópezPedrosa JM. Salacia oblonga extract increases glucose transporter 4-mediated glucose uptake in L6 rat myotubes: role of mangiferin. Clin Nutr. 2009 Oct;28(5):565 74. doi: 10.1016/j.clnu.2009.04.018. Epub 2009 May 23. PMID: 19477051

43. Yoshikawa M, Nishida N, Shimoda H, Takada M, Kawahara Y, Matsuda H. [Polypheno constituents from Salacia species: quantitative analysis of mangiferin with alphaglucosidase and aldose reductase inhibitory activities]. Yakugaku Zasshi. 2001 May;121(5):371-8. Japanese. doi: 10.1248/yakushi.121.371. PMID: 11360491.

44. Mujawdiya PK, Kapur S. Mangiferin: A potential natural molecule for managemen of metabolic syndrome. Int J Pharm Pharm Sci. 2015;7:9-13. https://bit.ly/3tzcKTx

45. Díaz-de-Cerio E, Verardo V, Gómez-Caravaca AM, Fernández-Gutiérrez A, SeguraCarretero A. Health Effects of Psidium guajava L. Leaves: An Overview of the Last
Decade. Int J Mol Sci. 2017 Apr 24:18(4):897. doi: 10.3390/ijms18040897. PMID: 28441777; PMCID: PMC5412476.

46. Muyenga TA, Musonda D, Chigunta M. Ethnobotanical Survey of MedicalPlants Used in Treatment of Diabetes in Chipulukusu Compound, Ndola District,Zambia. Journal of Preventive and Rehabilitative Medicine. 2018;1(1):39-44. doi: :10.21617/ jprm.2018.0101.5

47. Dahlgren JP, Ostergård H, Ehrlén J. Local environment and density-dependent feedbacks determine population growth in a forest herb. Oecologia. 2014 Dec;176(4):1023-32. doi: 10.1007/s00442-014-3073-9. Epub 2014 Sep 17. PMID: 25224800 .

48. Ching SM, Zakaria ZA, Paimin F, Jalalian M. Complementary alternative medicine use among patients with type 2 diabetes mellitus in the primary care setting: a crosssectional study in Malaysia. BMC Complement Altern Med. 2013 Jun 26:13:148. doi: 10.1186/1472-6882-13-148. PMID: 23802882; PMCID: PMC3701537.

49. Khalil SH, Zaki A, Ibrahim AM, El-Moughazi AM, Khater AM, Youssef AM, El-Sa'ed AT, Rashed EM. Pattern of use of complementary and alternative medicine among type 2 diabetes mellitus patients in Alexandria, Egypt. J Egypt Public Health Assoc. 2013 Dec;88(3):137-42. doi: 10.1097/01.EPX.0000440994.89503.45. PMID: 24374946.

50. ALAlami U, A Saeed K, A Khan M. Prevalence and Pattern of Traditional and Complementary Alternative Medicine Use in Diabetic Patients in Dubai, UAE. Arab Journal of Nutrition and Exercise (AJNE). 2017;2:118

51. Naja F, Mousa D, Alameddine M, Shoaib H, Itani L, Mourad Y. Prevalence and correlates of complementary and alternative medicine use among diabetic patients in Beirut, Lebanon: a cross-sectional study. BMC Complement Altern Med. 2014 Jun 6:14:185. doi: 10.1186/1472-6882-14-185. PMID: 24906634; PMCID: PMC4074134.

52. Shikov AN, Narkevich IA, Akamova AV, Nemyatykh OD, Flisyuk EV, Luzhanin VG Povydysh MN, Mikhailova IV, Pozharitskaya ON. Medical Species Used in Russia for the Management of Diabetes and Related Disorders. Front Pharmacol. 2021 Jul 20;12:697411. doi: 10.3389/fphar.2021.697411. PMID: 34354589; PMCID: PMC8330883.

53. Talaei B, Asghari G, Mirmiran P, Azizi F, Bahreini S. Knowledge, Attitude, and Practice of Diabetic Patients toward Herbal Products in Iran: A Cross-sectional Study. Journal of Nutrition and Food Security. 2019;4(3). doi: 10.18502/jnfs.v4i3.1307

54. Kelak JA, Cheah WL, Safii R. Patient's Decision to Disclose the Use of Traditional and Complementary Medicine to Medical Doctor: A Descriptive Phenomenology Study. Evid Based Complement Alternat Med. 2018 Feb 14;2018:4735234. doi: 10.1155/2018/4735234. PMID: 29636778; PMCID: PMC5832099.

55. Jang S, Kim KH, Sun SH, Go HY, Lee EK, Jang BH, Shin YC, Ko SG. Characteristics of Herbal Medicine Users and Adverse Events Experienced in South Korea: A Survey Study. Evid Based Complement Alternat Med. 2017;2017:4089019. doi: 10.1155/2017/4089019. Epub 2017 Apr 10. PMID: 28491107; PMCID: PMC5402245.

56. Shaw D, Graeme L, Pierre D, Elizabeth W, Kelvin C. Pharmacovigilance of herbal medicine. J Ethnopharmacol. 2012 Apr 10;140(3):513-8. doi: 10.1016/j. jep.2012.01.051. Epub 2012 Feb 9. PMID: 22342381

57. Larizgoitia I, Bouesseau MC, Kelley E. WHO Efforts to Promote Reporting of Adverse Events and Global Learning. J Public Health Res. 2013 Dec 1;2(3):e29. doi: 10.4081/ jphr.2013.e29. PMID: 25170500; PMCID: PMC4147748.

58. Toki T, Ono S. Spontaneous Reporting on Adverse Events by Consumers in the United States: An Analysis of the Food and Drug Administration Adverse Event Reporting System Database. Drugs Real World Outcomes. 2018 Jun;5(2):117-128. doi: 10.1007/ 40801-018-0134-0. PMID: 29725886: PMCID: PMC5984610.

How to cite this article: Hikaambo CN, Namutambo Y, Kampamba M, Mufwambi W, Kabuka R, Chulu M, Nanyangwe N, Banda M, Chimombe T, Muungo LT, Mudenda S. Prevalence and Patterns of Herbal Medicine Use among Type 2 Diabetes Mellitus Patients at the University Teaching Hospitals in Lusaka. J Biomed Res Environ Sci. 2022 Jan 20; 3(1): 074-081. doi: 10.37871/jbres1402, Article ID: JBRES1402, Available at: https://www.jelsciences.com/articles/jbres1402.pdf 